\title{
Frecuencia de la mutación 35delG del gen GJB2 (conexina 26) en una muestra de escolares sordos de Santiago
}

\author{
Frequency of the 35delG mutation of GJB2 (connexin 26) in a sample of deaf \\ school children in Santiago
}

Margarita Arancibia S', Roxana Ramírez N², Corina Farfán Rº, Mónica Acuña P4, Lucía Cifuentes $0^{5}$.

\begin{abstract}
RESUMEN
Introducción: Se estima que 1 de cada 1.000 niños presenta hipoacusia severa al nacimiento o en los primeros meses de vida y el $50 \%$ de las hipoacusias congénitas se relacionan con el gen de la conexina 26 (GJB2). En poblaciones caucásicas la variante patogénica 35delG del gen GJB2, que es la más frecuente, se encuentra en $30 \%$ de los pacientes con hipoacusia congénita no sindrómica. En Chile, la frecuencia de esta variante en escolares sordos no está descrita.

Objetivos: Estimar la frecuencia de la mutación 35delG del gen GJB2 en niños con sordera congénita no sindrómica y no atribuible a causas ambientales conocidas, de colegios especiales de Santiago. Correlacionar la presencia de 35delG con los antecedentes clínicos de estos niños.

Material y método: Se determinó la presencia de la mutación 35delG mediante PCR alelo específico y secuenciación automatizada en 81 escolares. Se buscó asociar la presencia de 35delG y los antecedentes clínicos de los niños mediante la prueba exacta de Fisher.

Resultados: En el grupo estudiado, el 11,25\% de los casos presentaron la variante $35 \mathrm{de} / \mathrm{G}$, siendo ésta más frecuente en los casos en que había antecedentes familiares de sordera. En 8 casos se encontró una variante considerada no patogénica V27I.

Conclusión: La frecuencia de la mutación 35delG fue inferior a lo esperado, probablemente debido al método de selección de los niños a estudiar (aquellos cuyos padres no referían causa conocida de sordera, lo cual no fue refrendado por exámenes de laboratorio que permitieran descartar enfermedades infecciosas u otras condiciones causantes de sordera).
\end{abstract}

Palabras claves: Sordera genética, conexina 26, GJB2, 35delG.

1 Médico del Servicio de Otorrinolaringología, Hospital San Juan de Dios.

Bioquímica, Programa Genética Humana, Facultad de Medicina Universidad de Chile.

Tecnóloga Médica en ORL, Escuela de Tecnología Médica, Facultad de Medicina, Universidad de Chile.

Tecnóloga Médica, Programa Genética Humana, Facultad de Medicina, Universidad de Chile.

Médico Genetista, Programa de Genética Humana, ICBM, Facultad de Medicina, Universidad de Chile. 


\section{ABSTRACT}

Introduction: Congenital hearing loss occurs in 1 in 1000 live births and $50 \%$ of these cases are related with mutations in the connexin26 gene (GJB2). The 35delG variant is the most common of the known pathogenic alleles in Caucasian populations, reaching a frequency of $30 \%$ among the non syndromic congenital deaf people. The frequency of this variant has not been described in Chilean deaf children.

Aim: To estimate the frequency of the 35delG GJB2 gene mutation in children with non syndromic congenital hearing loss of unknown etiology from deaf schools in Santiago, and to evaluate the association between clinical features of these children and the presence of the $35 \mathrm{del} G$ allele.

Material and method: The presence of the 35de/G mutation was studied by allele specific PCR and automatical sequencing in 81 children. The association between clinical issues and genotypes was explored by Fisher exact test.

Results: We found the $35 \mathrm{del} G$ variant in $11,25 \%$ of the children, this mutation was more frequent in familial cases than sporadic cases of deafness. We also found the V27I non pathogenic variant in 8 cases.

Conclusion: The frequency of the 35de/G mutation was lower than the expected, probably due to the criterion used to select the school children to be studied.

Key words: Genetic deafness, 26 connexine, GJB2, 35de/G.

\section{INTRODUCCIÓN}

Numerosos estudios han reportado una frecuencia de hipoacusia sensorioneural, en uno de cada 1.000 recién nacidos vivos ${ }^{1}$, de los cuales en $60 \%$ se asocia a una causa genética, y de ellas el $70 \%$ no forman parte de ningún síndrome ${ }^{2,3}$. De estas hipoacusias no sindrómicas $40 \%$ a $50 \%$ se relacionan con el gen GJB2 que codifica para la conexina 26, proteína que forma parte de canales intercelulares (gap junctions), los cuales son importantes para el reciclaje del potasio de la endolinfa coclear a través de la red de gap junctions ${ }^{4}$ que se extiende desde el epitelio coclear hasta el ligamento espiral y la estría vascular y de la cual se han descrito al menos 217 mutaciones hasta la fecha, siendo la variante patogénica $35 \mathrm{delG}$ la encontrada con más frecuencia ${ }^{5}$.

El gen GJB2 se encuentra en el brazo largo del cromosoma 13, y en él se han descrito decenas de mutaciones distintas: la mutación $35 \mathrm{del}$ G consiste en la deleción es decir la pérdida de una guanina en la posición 35 de este gen, lo que produce un corrimiento del marco de lectura, y en consecuencia la generación de un codón de término prematuro en el nucleótido 38. Al correrse el marco de lectura se modifica la secuencia de aminoácidos de la proteí- na, y por lo tanto la proteína que se forma puede ser no funcional 0 incluso truncada (más corta por la aparición prematura de un codón de término).

En poblaciones griegas e italianas se han encontrado entre $3,5 \%$ y $4 \%$ de portadores heterocigotos de la mutación $35 \mathrm{delG}$ entre la población normooyente, frecuencia que es un poco menor hacia el norte de Europa ${ }^{6}$. En Brasil el 10\% de las sorderas prelinguales autosómicas recesivas se deben a homocigosis para la mutación $35 \mathrm{delG}^{7}$. En Venezuela se encontró que el $27,5 \%$ de los pacientes con hipoacusia neurosensorial congénita era portador de esta mutación ${ }^{8}$, cifra similar a la registrada en un estudio argentino ${ }^{9}$. Se ha descrito una correlación entre severidad de la sordera y tipo de mutaciones en GJB2, pacientes con dos mutaciones truncadas tienen mayor compromiso de la audición, que pacientes con mutaciones de sentido erróneo. En escasas familias también se han descrito sorderas de herencia dominante que obedecen a una mutación heterocigota en GJB2 ${ }^{10}$. De hecho este gen también está involucrado en algunas formas de sordera sindrómica ${ }^{11-14}$.

En Chile existe escasa información respecto de estudios genómicos vinculados con sordera y no existen publicaciones respecto de la frecuencia de las mutaciones conocidas en el gen de la conexina 
26 en población chilena con hipoacusia. Este trabajo estima la frecuencia de la mutación 35delG en el gen de la conexina 26 en una población de escolares chilenos con hipoacusia sensorioneural congénita no sindrómica, no atribuible a causas ambientales u obstétricas y analiza la correlación entre la presencia de esta mutación con los antecedentes clínicos de estos niños como antecedentes familiares de sordera congénita, severidad de la hipoacusia, etc. Así mismo compara la frecuencia de la mutación 35delG en el gen de la conexina 26, encontrada en esta muestra chilena con datos publicados para otras poblaciones.

Las técnicas para evaluar la presencia de la alteración 35delG pueden ser a través de PCR alelo específico que permite hacer un screening de la presencia de la alteración o por secuenciación, que permite leer toda la secuencia de nucleótidos del gen de la conexina 26 y determinar cambios en las bases nitrogenadas.

Este trabajo fue antecedido en el año 2008, por un estudio en que realizamos un trabajo descriptivo en que se entrevistó a 423 integrantes de 4 colegios para sordos de Santiago, Santiago Apóstol, Anne Sullivan, Jorge Otte y San Francisco de Asís, cubriendo al $90 \%$ de la población asistente. Se realizaron encuestas a apoderados y revisión de fichas de los colegios extrayendo información sobre causa probable de la hipoacusia, audiometrías, existencia de familiares hipoacúsicos, entre otras. Casi $60 \%$ de los niños no tenían causa conocida de su hipoacusia y de ellos 8\% tenía antecedente de algún familiar hipoacúsico.

Hipótesis: El 30\% de los escolares chilenos con sordera congénita sensorioneural no sindrómica son portadores de la mutación $35 \mathrm{delG}$ en el gen de la conexina 26. Esta mutación se presenta con mayor frecuencia en los casos familiares de sordera que en los casos esporádicos.

\section{OBJETIVOS}

Estimar la frecuencia de la mutación 35delG del gen GJB2 (conexina 26) en niños con sordera no sindrómica, no atribuible a causas infecciosas ni perinatales, asistentes a las escuelas de sordos Jorge Otte, Ann Sullivan y San Francisco de Asís de Santiago

\section{Objetivos específicos}

- Genotipificar los niños con sorderas no sindrómicas de origen desconocido para la mutación 35delG del gen de la conexina 26 mediante PCR alelo específico y corroboración con secuenciación de ADN.

- Correlacionar la presencia de la mutación señalada con la severidad de la sordera y la existencia de antecedentes familiares de hipoacusia congénita.

- Comparar la frecuencia de la mutación 35delG del gen de la conexina 26 estimada en nuestra muestra con la publicada para otras poblaciones humanas.

\section{MATERIAL Y MÉTODO}

Se envió encuesta a apoderados de escolares de los colegios subvencionados para sordos en Santiago: Jorge Otte, Anne Sullivan y San Francisco de Asís (Colegio Santiago Apóstol no fue incluido porque estos niños ya habían participado en un estudio hecho por otro centro), se solicitó consentimiento para que su hijo-a participara en este estudio, también se le solicitó asentimiento a los niños mayores de 12 años, se evaluaron antecedentes tanto del hijo como familiares, entregados por los apoderados a través de la encuesta enviada por escrito. Se revisaron audiometrías registradas en el colegio. Este estudio fue aprobado por el Comité de Ética de la Facultad de Medicina de la Universidad de Chile.

\section{Extracción de ADN y determinación de mutaciones de 35deIG}

\section{a. Extracción de ADN de hisopado de mucosa bucal:}

Técnica descrita por Miller y cols (1998) ${ }^{15}$, de cada participante en el estudio se obtuvo un hisopado de mucosa bucal; se cortó la zona externa del algodón y se colocó en un tubo de 1,6 mL. Se adicionó $300 \mu \mathrm{L}$ de solución SEB (stain extraction buffer), 11,7 $\mu \mathrm{L}$ de DTT $1 \mathrm{M}$ y $7,5 \mu \mathrm{L}$ de proteinasa $\mathrm{K}(20 \mathrm{mg} / \mathrm{mL})$. Se incubó toda la noche a $56^{\circ} \mathrm{C}$. Posteriormente, se retiró el algodón y se agregó 300 uL de una solución de fenol-cloroformoalcohol isoamílico (25:24:1), se agitó en vortéx y 
se centrifugó. El sobrenadante obtenido se purificó por Microcon ${ }^{\circledR}$.

\section{b. - Genotipifición de la variante 35delG mediante la técnica PCR alelo específico}

Esta técnica consiste en la amplificación de la región polimórfica a través de dos PCR: una PCR para identificar el alelo silvestre (PCR-N) y otra para identificar el alelo 35delG (PCR-M). Para ello se utilizaron tres partidores: uno denominado $\mathrm{C}$, partidor común para ambas PCR; un partidor N para la PCR-N y un partidor M para la PCR-M (Scott y cols, 1998) ${ }^{16}$ (Figura 1).

Los productos de PCR fueron sometidos a una electroforesis en gel de agarosa al 1,5\% y teñidos con bromuro de etidio para su visualización. La presencia del alelo silvestre y del alelo $35 \mathrm{delG}$ se determinó por la amplificación (202pb) de la PCR-N y PCR-M, respectivamente; la ausencia de un alelo determinado está dada por la no amplificación de la PCR específica.

\section{c.- Genotipificación mediante secuenciación automática del exón 2 del gen GJB2}

Las muestras de ADN se secuenciaron, después de haber amplificado el ADN de la región correspondiente al exón 2 del gen GJB2 (el exón 2 codifica para la conexina 26 completa), utilizando un set de partidores externos y otro set de partidores internos de acuerdo a Wu y cols $(2003)^{17}$.

Los cromatogramas obtenidos de la secuenciación se analizaron de acuerdo con la información existente en la base de datos Gen Bank de NCBI (número de acceso: M86849).
Se estimó la frecuencia de la mutación 35delG en los niños con hipoacusia congénita de causa desconocida y se hicieron comparaciones entre grupos mediante prueba exacta de Fisher.

\section{RESULTADOS}

Se recibieron antecedentes de 278 niños, en la mayor parte de los casos la causa de la sordera era desconocida $(60 \%)$. Dentro de las causas conocidas, las causas infecciosas ocuparon un importante lugar $(20 \%)$ e incluyeron meningitis, rubéola y otras infecciones graves. Se seleccionaron 81 niños con sordera no sindrómica de origen desconocido, que cumplían con los requisitos de consentimiento informado y antecedentes clínicos, para el estudio de la mutación 35delG. En una primera etapa se genotipificó la mutación 35delG mediante PCR alelo específico en estos 81 niños. En 15 de estos análisis no se obtuvo amplificación del ADN. En una segunda etapa se envió a secuenciar el exón 2 completo del gen de la conexina 26, en aquellos niños en que no se había obtenido amplificación de ADN, en todos los niños que habían resultados ser portadores de la mutación $35 \mathrm{delG}$ con la técnica alelo específica $(n=12)$ y en una muestra aleatoria de niños con genotipo normal según la técnica de PCR alelo específica $(n=8)$, con el fin de corroborar los resultados. Mediante secuenciación automática (Figura 2) se logró identificar la mutación 35delG en 9 de los 80 casos, lo que corresponde al $11,25 \%$ de la muestra (Tabla 1), 2/3 de los casos fueron homocigotos y en la Figura 2 se muestra un cromatograma donde se observa la deleción de guanina en la posición 35. Los resulta-

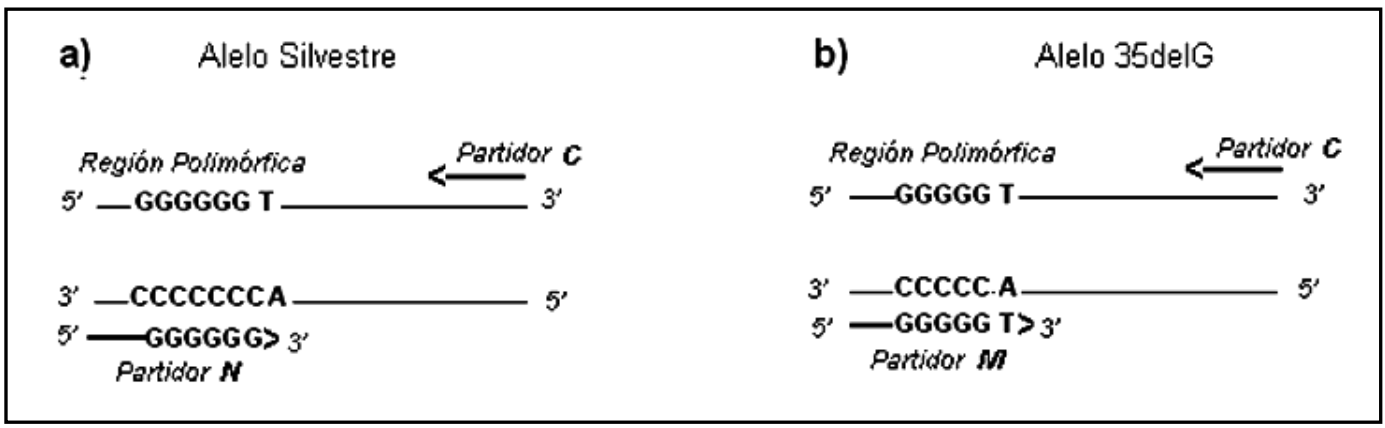

Figura 1. Esquema de amplificación: a) PCR alelo silvestre ; b) PCR alelo 35delG. 


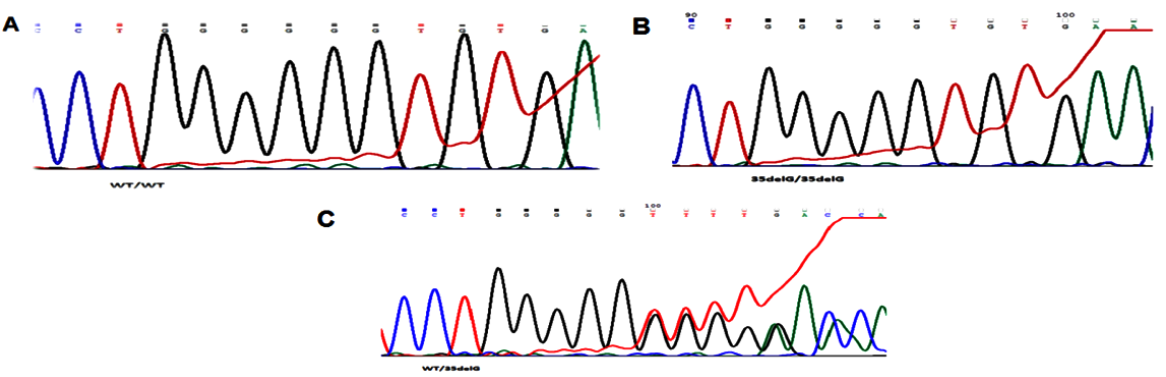

Figura 2. Cromatograma de la región polimórfica 35delG. A. homocigosis alelo silvestre, B. homocigosis alelo 35 delG, C. heterocigosis alelo silvestre y alelo 35delG.

Tabla 1. Genotipos para el gen de la conexina 26 en 80 escolares con sordera no sindrómica

\begin{tabular}{|lccccc|}
\hline $\begin{array}{l}\text { Genotipo } \\
\text { Colegio }\end{array}$ & $\begin{array}{c}\text { Normal } \\
\text { wt/wt }\end{array}$ & 35delG/35delG & Wt/35delG & (variante V27I) & Total \\
\hline J. Otte & 24 & 3 & 0 & 5 & 32 \\
S. Francisco & 27 & 0 & 2 & 1 & 30 \\
A. Sullivan & 12 & 3 & 1 & 1 & 18 \\
Total & 63 & 6 & 3 & 8 & 80 \\
\hline
\end{tabular}

dos finales de genotipificación considerando la información obtenida por secuenciación del exón 2, permitió detectar también otra variante (no patogénica), la V27I que corresponde a la sustitución de una isoleucina en el sitio de una valina debido a un cam- bio de $G$ por $A$ en el ADN, en 8 casos (Figura 3). En 1 caso no hubo amplificación de ADN.

Los niños con la mutación 35delG tenían antecedentes de parientes sordos, con mayor frecuencia $(55 \%)$, que los niños sin la mutación $(26,9 \%)$,

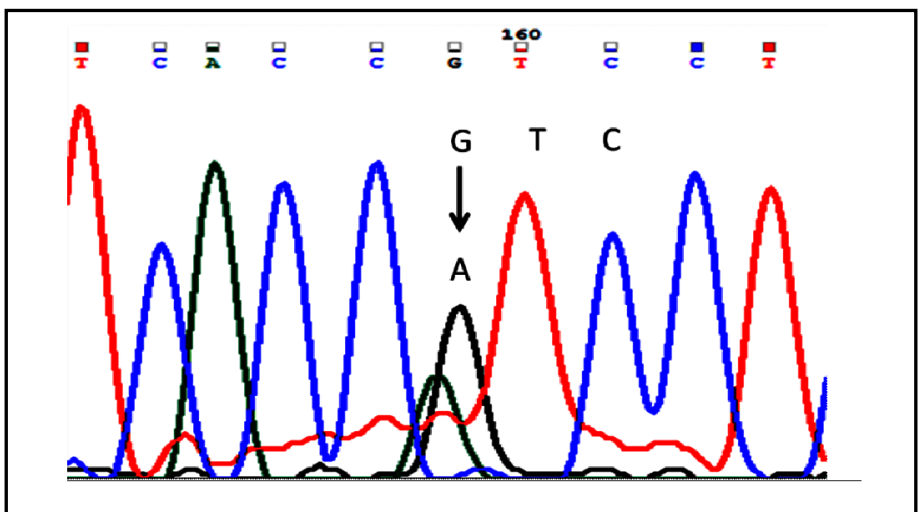

Figura 3. Cromatograma de la región del codón 27 del gen GJB2. Se indica con una flecha el cambio nucleotídico de G por A. Este paciente es heterocigoto para el cambio G por A en esta región de la secuencia. 
aunque esta diferencia no alcanzó una diferencia estadísticamente significativa; $p=0,059$ (Tabla 2).

En relación al grado de la hipoacusia, en $24,4 \%$ de los pacientes sordos profundos y en $14,3 \%$ de aquellos con sordera moderada se encontró la deleción; en este caso no hubo diferencia estadísticamente significativa. Tabla 3.

\section{DISCUSIÓN}

Actualmente en Chile no hay publicaciones sobre genotipificación del gen GJB2, es por ello que este estudio abre una puerta de investigación, para evaluar esta causa en nuestro país.

Se conocen factores de riesgo para hipoacusia congénita, entre ellos antecedentes familiares de hipoacusia ${ }^{18}$. En nuestro grupo de niños evaluados tanto con técnica de PCR, como por secuenciación, es más frecuente la deleción cuando hay antecedentes familiares de sordera, $55 \%$ vs $26,9 \%$, aunque esta diferencia no alcanzó una diferencia estadísticamente significativa; $p=0,059$.
La frecuencia de $11,25 \%$ de portadores de la mutación 35delG en escolares sordos, es algo más baja que la reportada en otras poblaciones latinoamericanas (23,5\% en Brasil, 26,5\% en Argentina) $)^{7,9}$, probablemente debido al método de selección de los niños para ser estudiados: en el presente trabajo se estudiaron niños que, de acuerdo a la información entregada por sus apoderados en una encuesta escrita, presentaban sordera de origen desconocido, en cambio en los otros estudios publicados se catalogaba la sordera como de origen desconocido si los exámenes clínicos y de laboratorio no permitían identificar una causa.

No encontramos asociación entre la presencia de la mutación y la severidad de la hipoacusia.

Consideramos que así, como se realiza un tamizaje en los niños prematuros incorporados en la ley de Garantías Explícitas de Salud, es una buena alternativa agregar al screening auditivo, niños con riesgo como el publicado por el Instituto Norteamericano de Salud, especialmente en los casos en que hay antecedentes familiares de hipoacusia. Realizar estudio de secuenciación del gen GJB2 en estos

Tabla 2. Asociación entre la presencia de la mutación 35delG y la existencia de parientes sordos

\begin{tabular}{|lccccc|}
\hline $\begin{array}{l}\text { Genotipo } \\
\text { Antec Fam }\end{array}$ & $\begin{array}{c}\text { Normal } \\
\text { wt/wt }\end{array}$ & 35delG/35delG & 35delG/wt & (variante V27l) & Total \\
\hline Sí & 17 & 4 & 1 & 1 & 23 \\
No & 46 & 2 & 2 & 7 & 57 \\
Total & 63 & 6 & 3 & 8 & 80 \\
\hline
\end{tabular}

Tabla 3. Asociacion entre mutación 35delG y la profundidad de la sordera

\begin{tabular}{|lccccc|}
\hline $\begin{array}{l}\text { Genotipo grado } \\
\text { sordera }\end{array}$ & $\begin{array}{c}\text { Normal } \\
\text { wt/wt }\end{array}$ & 35delG/35delG & 35delG/wt & Otro & Total \\
\hline Moderada & 4 & 0 & 0 & 0 & 4 \\
Severa & 14 & 3 & 0 & 3 & 20 \\
Profunda & 38 & 3 & 3 & 4 & 48 \\
Total & 56 & 6 & 3 & 7 & 72 \\
\hline
\end{tabular}

Nota: Los números totales son inferiores a 80 , ya que existían niños sin audiometría. La gravedad de la sordera no se asocia con el genotipo $(P=0,7)$. 
pacientes especialmente aquellos que tienen antecedentes familiares, apoyaría a la decisión de realizar un implante coclear ya que se han reportado mejores resultados en estos casos ${ }^{19,20}$.

\section{CONCLUSIONES}

En el grupo estudiado se detectó $11,25 \%$ de presencia de la variante $35 \mathrm{delG}$, inferior a lo reportado por otros estudios en otros países latinoamericanos.

La variante $35 \mathrm{del} G$ es más frecuente en los casos en que hay antecedentes familiares de sordera.

En 8 casos se encontró una variante considerada no patogénica V27I.

\section{Agradecimientos}

A la Dra. Mariela Torrente por su apoyo y presentación de este trabajo en el Congreso de la SOCHIORL, a la bioquímica Carolina Ríos por su apoyo en laboratorio, al Dr. Hayo Breinbauer, a los alumnos de medicina de la Universidad de Chile Adriano Razeto y Camila Pinochet y de la Universidad de Los Andes Camila Galaz, por su ayuda en la recolección de datos y encuestas a apoderados en los colegios visitados, y especialmente a los directores de los colegios que amablemente nos recibieron y facilitaron las instalaciones para realizar nuestro trabajo.

Trabajo realizado en la Facultad de Medicina, Departamento Programa Genética Humana, Universidad de Chile.

Trabajo financiado parcialmente a través del concurso anual de investigación de la Sociedad Chilena de Otorrinolaringología de Medicina y Cirugía de Cabeza y Cuello.

\section{BIBLIOGRAFÍA}

1. LIM L, GReINwaLd J. Current status of genetics in the evaluation and management of SNHL. Curr Opin Otolaryngol Head Neck Surg 2002; 10: 435-9.

2. Resendes BL, Williamson Re Morton CC. At the speed of sound: Gene discovery in the auditory system. Am J Hum Genet 2001; 69: 923-5.

3. Tseng CJ, Lalwani AK. Cracking the auditory genetic code: Part II. Syndromic hereditary hearing impairment. Am J Otol 2000; 21: 43751.

4. Van Laer L, Cryns K, Smith R, Van Camp G. Nonsyndromic hearing loss. Ear Hear 2003; 24: 275-88.

5. The Human Gene Mutation Database at the Institutu of Medical Genetic; http:// www.hgmd.cf.ac.uk/ac/index.php, revisión junio 2011.

6. Pampanos A, Economides J, Iliadou V et al. Prevalence of GJB2 mutations in prelingual deafness in the Greek population. Int J Pediat Otorhinolaringol 2002; 65: 101-8.

7. Oliveira CA, Maciel-Guerra at, Sartorato El. Deafness resulting from mutations in GJB2 (connexin 26) gene in Brazilian patients. Clin Genet 2002; 61: 354-8.

8. Utrera R, Ridaura V, Rodríguez Y et al. Detection of the 35delG/GJB2 and del(GJB6-D13S1830) mutations in Venezuelan patients with autosomal recessive nonsyndromic hearing loss. Genet Testing 2007; 11 (4): 347-52.

9. Dalamón V, Beheran A, Diamante Fet al. Prevalence of GJB2 mutations and the del(GJB6-D13S1830) in Argentinean nonsyndromic deaf patients. Hear Res 2005; 207: 43-9.

10. Willems PJ. Genetic hearing loss. New Cork, Basel: Marcel Dekker, Inc, 2004.

11. Heathcote K, Syrris P, Carter ND et al. A connexin 26 mutation causes a syndrome of sensorioneural hearing loss and palmoplantar hyperkeratosis (MMIM 148350). J Med Genet 2000: 37: 50-1.

12. KeLSELL DPW-L, Houseman MJ. Conexin mutations in skin disease and hearing loss. Am J Hum Genet 2001; 68: 559-68.

13. Richard G, Rouan F, Willoughby CE et al. Missense mutations in GJB2 encoding connexin-26 cause the ectodermal dysplasia keratitis-ichthyosisdeafness syndrome. Am J Hum Genet 2002; 70: 1341-8.

14. Venall F, Roux A, Pallares-Ruiz N. Nonsyndromic $35 \mathrm{del} G$ mutation of the connexin 26 gene associated with deafness in syndromic children: Two case reports. Laryngoscope 2004; 114: 566-9. 
15. Miller SA, Dykes D, Polesky H. A simple salting out procedure for extracting DNA from Human nucleated cells. Nucleids Acid Res 1998; (16): 1215.

16. Scott D, Kraft M, Carmi R, Ramesh A, Elbedour K, YairI Y, SRIKumari Srisallapathy C, Rosengren S, Markham A, Mueller R, Lench N, Van Camp G, Smith $\mathrm{R}$, SHeFfIeLd V. Identification of mutations in the connexin 26 gene that cause autosomal recessive nonsyndromic hearing loss. Hum Mut 1998; 11: 387-94.

17. Wu B, Kenna M, Lip V, Irons M, Platt 0. Use of a multiplex PCR/sequencing strategy to detect both connexion 30 (GJB6) $342 \mathrm{~kb}$ deletion and connexin 26 (GJB2) mutations in cases of childhood deafness. Am J Med Genet 2003; 121A: 102-8.

18. American Academy of Pediatrics. Position stament 1982-Joint Committee on Infant Hearing. Pediatrics 1982; Vol 70: 496-7.

19. Sмітн R. Mutations screening for deafness. Arch Otolaryngol Head Neck Surg 2001; 127: 941-2.

20. Bauer P, Geers A, Brenner C, Moog J, Smith R. The effect of GJB2 allele variants on performance after cochlear implantation. Laryngoscope 2003; 113: $2135-40$. 